\title{
Systemic inflammatory markers have independent prognostic value in patients with metastatic testicular germ cell tumours undergoing first-line chemotherapy
}

Christian Daniel Fankhauser ${ }^{1,4}$, Sophia Sander ${ }^{1,4}$, Lisa Roth ${ }^{1}$, Oliver Gross ${ }^{1}$, Daniel Eberli ${ }^{1}$, Tullio Sulser ${ }^{1}$, Burkhardt Seifert ${ }^{2}$, Joerg Beyer ${ }^{\star}, 3$ and Thomas Hermanns ${ }^{1}$

${ }^{1}$ Department of Urology, University Hospital, University of Zurich, Zurich 8091, Switzerland; ${ }^{2}$ Epidemiology, Biostatistics and Prevention Institute, University of Zurich, Zurich 8001, Switzerland and ${ }^{3}$ Department of Oncology, University Hospital, University of Zurich, Zurich 8091, Switzerland

Background: The prognostic utility of systemic inflammatory markers has so far not been investigated in patients with metastatic testicular germ cell tumours (GCTs).

Methods: International Germ Cell Cancer Cooperative Group (IGCCCG) risk groups and blood-based systemic inflammatory markers (haemoglobin, leukocytes, platelets (P), neutrophils (N), lymphocytes (L), C-reactive protein (CRP) and albumin) of 146 patients undergoing first-line chemotherapy for GCT were retrieved. In addition, $N$ to $L$ ratio (NLR), $P$ to $L$ ratio and the systemic immune-inflammation index $(\mathrm{SII}=\mathrm{N} \times \mathrm{P} / \mathrm{L})$ were calculated. The prognostic ability of these markers for overall survival (OS) were assessed using regression analyses and Kaplan-Meier curves with log-rank tests.

Results: In univariate Cox regression, low haemoglobin and albumin as well as high leukocytes, N, NLR, SII and CRP were associated with a shorter OS. In multivariable Cox regression analyses, high leukocyte (hazard ratio (HR) 1.274 (95\% confidence interval $(C I) 1.057-1.535) ; P=0.011)$ and $N$ count (1.470 (1.092-1.980); $P=0.011)$, higher NLR (84.5 (2.2-3193.4); $P=0.017)$ and SII (12.15 (1.17-126.26); $P=0.037$ ) remained independent prognostic predictors for OS besides the IGCCCG risk groups.

Conclusions: Systemic inflammatory markers might have prognostic utility for patients with metastatic GCT. The planned IGCCCG update could be an opportunity to test these markers in a larger data set.

An estimated number of 8850 new cases of germ cell tumours (GCTs) will be diagnosed in the United States in 2017 (Siegel et al, 2017). Thirty percent of all patients present with metastases at initial diagnosis (DeSantis et al, 2014). An additional 15-30\% develop metastatic disease recurrence during follow-up (Daugaard et al, 2014; Chung et al, 2015). Although metastatic GCTs usually respond very well to cisplatin-based chemotherapy, $10-15 \%$ of patients fail first-line treatment and 3-5\% of all GCT patients will eventually die of their disease (Gandaglia et al, 2014).

In 1997, the International Germ Cell Cancer Cooperative Group (IGCCCG) published a prognostic classification system for patients with metastatic GCT, which is currently used to determine the treatment algorithm for these patients (International-Germ-CellCancer-Collaborative-Group, 1997). The histological subtype

*Correspondence: Professor J Beyer; Email: joerg.beyer@usz.ch

${ }^{4}$ These authors contributed equally to this work.

Received 22 September 2017; revised 24 November 2017; accepted 27 November 2017; published online 27 February 2018

(C) 2018 Cancer Research UK. All rights reserved 0007-0920/18 
(seminoma $v s$ non-seminoma), the location of the primary tumour, the extent of metastatic spread as well as the level of the tumour markers alpha-fetoprotein (AFP), beta-human chorionic gonadotropin (HCG) and lactate dehydrogenase $(\mathrm{LDH})$ are used in this classification system, which divides patients with metastases into groups of either good, intermediate or poor risk.

Inflammation is known to play an important role in the biology of many tumours and is considered a hallmark of cancer (Grivennikov and Karin, 2010; Hanahan and Weinberg, 2011). Several markers of systemic inflammation (e.g., leucocytes, neutrophils, thrombocytes) can be obtained from routine blood tests such as the complete blood count (CBC). Some of these markers and particularly ratios of different markers have been shown to be of prognostic value in various malignancies including genitourinary cancers such as urothelial cancer, kidney cancer and prostate cancer (Yamanaka et al, 2007; Sarraf et al, 2009; Azab et al, 2012; Ishizuka et al, 2013; Hermanns et al, 2014; Templeton et al, 2014b; Bhindi et al, 2016). However, the prognostic utility of different systemic inflammatory markers for patients with testicular cancer has yet to be elucidated.

For patients with metastatic GCTs, inflammatory markers could add prognostic information to the well-established IGCCCG prognostic system. Thus, the aim of the present investigation was to assess whether different inflammatory markers obtained from routine blood tests are independent predictors of oncologic outcome besides the IGCCCG prognostic system.

\section{PATIENTS AND METHODS}

We identified patients who underwent first-line chemotherapy for metastatic GCT at our institution between 2000 and 2015. We excluded patients with extragonadal GCT, bilateral testicular GCT, missing systemic inflammatory markers or missing follow-up information. Pre-chemotherapy baseline characteristics (age, body mass index, histology of the primary tumour, TNM stage and IGCCCG risk groups) and results from routine pre-chemotherapy blood tests were retrieved from our electronic medical records. Blood tests included the tumour markers AFP, HCG and LDH. Furthermore CBC-based systemic inflammatory markers such as haemoglobin, platelets (P), leukocytes, lymphocytes (L), and neutrophils $(\mathrm{N})$ as well as non-CBC markers (C-reactive protein (CRP) and albumin) were extracted. In addition, the neutrophil-tolymphocyte ratio (NLR), the platelet-to-lymphocyte ratio (PLR) and the systemic immune-inflammation index $(\mathrm{SII} ; \mathrm{N} \times \mathrm{P} / \mathrm{L})$ were calculated. The survival status of the patients was identified from death certificates or medical charts. The overall survival (OS) was measured from the date of initial chemotherapy to the date of death from any cause. Patients were censored at the date of last follow-up. The local ethics committee approved the study protocol and waived informed consent (STV KEK-ZH 25-2008).

We performed a univariate Cox regression analysis to assess the association between IGCCCG risk groups, systemic inflammatory markers and OS. Several multivariable Cox regression analyses including IGCCCG risk groups and each individual systemic inflammatory marker separately were performed to assess the incremental prognostic information of each marker in addition to the IGCCCG risk groups. Due to the low rate of events, we were not able to perform a single multivariable regression analysis including the IGCCCG risk groups and all relevant systemic inflammatory markers. Systemic inflammatory markers in univariate and multivariable analyses were evaluated as continuous variables. AFP, HCG, LDH, NLR, PLR, SII and CRP were logtransformed due to their skewed distribution.

Because clinical decision-making is facilitated by defined cutoff values, we performed raw receiver operating curve (ROC) analyses using the maximal Youden's index (= sensitivity + specificity -1$)$ (Youden, 1950) to determine an optimal cutoff value. KaplanMeier analyses with log-rank tests were used to compare survival outcomes between patients with systemic inflammatory markers above $v s$ below the optimal cutoff point.

To assess whether more advanced disease is associated with higher values of the systemic inflammatory markers in patients with metastatic GCTs, a subgroup analysis comparing patients with or without brain, bone and visceral metastases was performed.

Statistical analyses were performed using SPSS Statistics version 21.0 (IBM Corp., Armonk, NY, USA). The results for continuous normally distributed variables are expressed as mean \pm s.d. Continuous non-normally distributed variables are presented as median and interquartile ranges (IQRs) and categorical variables are presented as percentage. All $P$-values $<0.05$ were considered statistically significant. All statistical tests were two-sided.

\section{RESULTS}

The baseline characteristics of all 146 patients are summarised in Table 1. Thirty-seven patients presented with seminoma and 108 patients with non-seminoma. Sixty-one patients (42\%) were classified as clinical stage II and 85 patients (58\%) as clinical stage III. Ninety-seven patients (66\%) were classified as IGCCCG good risk, 26 patients $(18 \%)$ as intermediate and 23 patients $(16 \%)$ as poor risk. Median follow-up was 53 months (IQR: 23-91 months). After first-line chemotherapy response evaluation was available in 130 patients. Complete remission was achieved in 49 patients (38\%), partial remission in 55 patients (42\%), stable disease in two patients $(2 \%)$ and progressive disease in three patients $(2 \%)$. Retroperitoneal lymph-node dissection was performed in 21 nonseminoma patients because of a post-chemotherapy residual mass. Overall, 42 patients (29\%) progressed or relapsed after first-line chemotherapy. Twenty-eight of these patients (67\%) received salvage chemotherapy, 11 patients (26\%) underwent surgical resections of metastases in the lung $(n=6)$, liver $(n=2)$ or nonretroperitoneal lymph-nodes $(n=3)$ and 4 patients $(10 \%)$ underwent radiotherapy. A total of 17 patients (12\%) died during follow-up.

In univariate Cox regression analysis, low-serum haemoglobin (hazard ratio (HR) 0.962 (95\% confidence interval $(\mathrm{CI})=0.942-$ $0.982) ; P<0.001)$ and low albumin levels (HR: $0.844 \quad(95 \%$ $\mathrm{CI}=0.742-0.961) ; P=0.010)$ as well as elevated leukocytes (HR 1.136 (95\% CI $=1.141-1.565) ; P<0.001)$ or neutrophils (HR: $1.611(95 \% \mathrm{CI}=1.232-2.105) ; P<0.001)$ as well as a higher NLR (HR per 10-fold increase: 73.05 (95\% CI 3.70-1442.25); $P=0.005)$, a higher SII (HR per 10-fold increase: 30.20 (95\% CI $=3.00-$ 304.21); $P=0.004)$ and a higher CRP (HR $6.44(95 \% \mathrm{CI}=2.04-$ 20.29); $P=0.001$ ) were associated with a shorter OS (Table 2). A significant association of platelet and lymphocyte counts or PLR with OS could not be detected.

In multivariable analyses that included one individual systemic inflammatory marker and the IGCCCG risk groups leukocyte count (HR per 10-fold increase: 1.274 (95\% CI =1.057-1.535); $P=0.011)$, neutrophil count (HR per 10-fold increase: $1.470(95 \%$ $\mathrm{CI}=1.092-1.980) ; P=0.011)$, NLR (HR per $10 \times$ increase: 84.5 $(95 \% \mathrm{CI}=2.2-3193.4) ; P=0.017)$ and SII (HR per $10 \times$ increase: 12.15 (95\% CI $=1.17-126.26) ; P=0.037)$ remained independent predictors of OS besides the IGCCCG risk groups. Haemoglobin, CRP and albumin could not be confirmed as independent prognostic variables (see Table 3 ).

In order to define cutoff values for clinical decision-making ROC analyses revealed ideal cutoff points for leukocytes at $11.610^{3}$ per $\mu \mathrm{l}$ (AUC 0.755 (95\% CI 0.602-0.908); $P=0.006$ ), for neutrophils at $5.110^{3}$ per $\mu$ l (AUC 0.755 (95\% CI 0.633-0.917); 
Table 1. Baseline characteristics

\begin{tabular}{|c|c|}
\hline & $N=146$ \\
\hline Age (years) ( $\pm \mathrm{SD})$ & $34(9)$ \\
\hline $\mathrm{BMI}\left(\mathrm{kg} \mathrm{cm}^{-2}\right)( \pm \mathrm{SD})$ & $25(5)$ \\
\hline Seminoma $n(\%)$ & $37 / 146(25 \%)$ \\
\hline Non-seminoma n (\%) & 108/146 (74\%) \\
\hline Unknown n (\%) & $1 / 146(<1 \%)$ \\
\hline $\begin{array}{l}\text { Clinical stage } \\
\text { Stadium II n (\%) } \\
\text { Stadium III n (\%) }\end{array}$ & $\begin{array}{l}61 / 146(42 \%) \\
85 / 146(58 \%)\end{array}$ \\
\hline $\begin{array}{l}\text { IGCCCG risk groups } \\
\text { Good risk } n(\%) \\
\text { Intermediate risk } n(\%) \\
\text { Poor risk } n(\%)\end{array}$ & $\begin{array}{l}97 / 146(66 \%) \\
26 / 146(18 \%) \\
23 / 146(16 \%)\end{array}$ \\
\hline $\begin{array}{l}\text { Site of metastases } \\
\text { Retroperitoneal lymph nodes } \\
\text { Lung } \\
\text { Mediastinal } \\
\text { Neck } \\
\text { Visceral } \\
\text { Bone } \\
\text { Brain } \\
\text { Other }\end{array}$ & $\begin{array}{c}134 / 146(92 \%) \\
61 / 146(42 \%) \\
36 / 146(25 \%) \\
18 / 146(12 \%) \\
11 / 146(8 \%) \\
4 / 146(3 \%) \\
3 / 146(2 \%) \\
9 / 146(6 \%)\end{array}$ \\
\hline $\operatorname{AFP}\left(\mu \mathrm{gl}^{-1}\right)(\mathrm{IQR})$ & $5.70(2.75-143.50)$ \\
\hline $\mathrm{HCG}\left(\mathrm{UI}^{-1}\right)(\mathrm{IQR})$ & $7.70(0.0-1021.1)$ \\
\hline $\mathrm{LDH}\left(\mathrm{UI}^{-1}\right)(\mathrm{IQR})$ & 445 (324-771) \\
\hline Haemoglobin $\left(\mathrm{gl}^{-1}\right)$ (IQR) & $146(133-157)$ \\
\hline Leukocytes $\left(10^{3}\right.$ per $\left.\mu \mathrm{l}\right)( \pm \mathrm{SD})$ & $7.54(2.61)$ \\
\hline Thrombocytes $\left(10^{3}\right.$ per $\left.\mu \mathrm{l}\right)( \pm \mathrm{SD})$ & $289(100)$ \\
\hline Neutrophils $\left(10^{3}\right.$ per $\left.\mu \mathrm{l}\right)( \pm \mathrm{SD})$ & $5.08(2.10)$ \\
\hline Lymphocytes $\left(10^{3}\right.$ per $\left.\mu l\right)( \pm S D)$ & $1.47(0.52)$ \\
\hline $\operatorname{CRP}\left(\left.m g\right|^{-1}\right)(I Q R)$ & $5.00(1.00-20.25)$ \\
\hline Albumin (IQR) & $43(39-46)$ \\
\hline NLR (IQR) & $3.18(2.34-5.07)$ \\
\hline PLR (IQR) & $182(133-167)$ \\
\hline SII (IQR) & $898(511-1520)$ \\
\hline \multicolumn{2}{|c|}{$\begin{array}{l}\text { Abbreviations: AFP = alpha-fetoprotein; } \mathrm{BMI}=\text { body mass index }\left(\mathrm{kg} \mathrm{cm}^{-2}\right) ; \mathrm{CRP}=\mathrm{C} \text {-reactive } \\
\text { protein }\left(\mathrm{mg} \mathrm{I}^{-1}\right) ; \mathrm{HCG}=\text { beta-human chorionic gonadotropin; } \mathrm{IGCCCG}=\text { International Germ } \\
\text { Cell Cancer Collaborative Group; IQR = interquartile range; } \mathrm{LDH}=\text { lactate dehydrogenase } \\
\left(\mathrm{U} \mathrm{I}^{-1}\right) \text {; NLR=neutrophil-to-lymphocyte ratio; PLR= platelet-to-lymphocyte ratio; SII = } \\
\text { systemic immune-inflammation index. }\end{array}$} \\
\hline
\end{tabular}

$P=0.005$ ), for NLR at 4.5 (AUC 0.811 (95\% CI 0.693-0.930); $P=0.001$ ) and for SII at 1428 (AUC 0.797 (95\% CI 0.646-0.947); $P=0.002)$. Kaplan-Meier curves and log-rank tests confirmed that high leukocyte and neutrophil counts as well as high NLR and SII were associated with worse prognosis (all $P<0.001$ ) (Figure 1).

A subgroup analysis comparing inflammatory markers between patients with to patients without brain, bone and visceral metastases revealed significantly higher levels of leukocytes (8.9 vs $6.810^{3}$ per $\left.\mu \mathrm{l}, P<0.01\right)$ and neutrophils $\left(7.1\right.$ vs $4.510^{3}$ per $\mu$, $P<0.01)$ but no significant differences for $\operatorname{NLR}(P=0.062)$ or SII $(P=0.057)$.

\section{DISCUSSION}

The majority of patients diagnosed with metastatic GCT can be cured due to highly effective chemotherapy treatments. Using the IGCCCG classification, patients can be allocated into three risk groups that are widely used to determine the intensity of systemic first-line treatment. However, despite IGCCCG risk prediction and
Table 2. Univariate Cox regression analysis

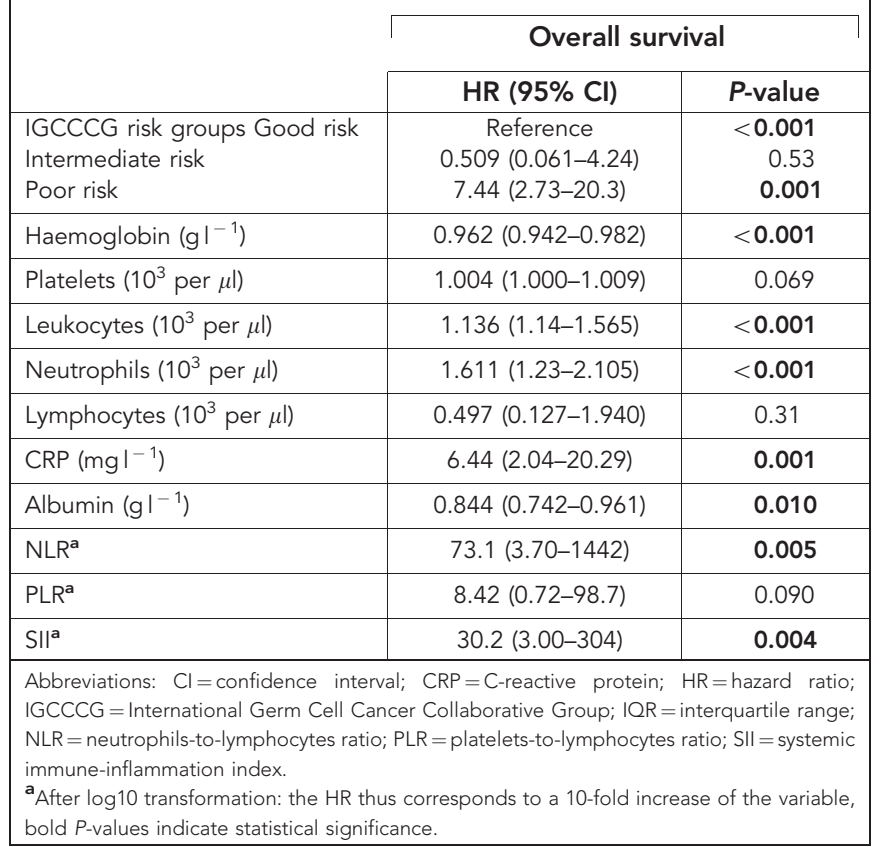

Table 3. The incremental prognostic information of each marker was assessed by performing separate multivariable Cox regression analyses including each marker and the IGCCCG risk groupings

\begin{tabular}{|c|c|c|}
\hline & \multicolumn{2}{|c|}{ Overall survival } \\
\hline & HR $(95 \% \mathrm{Cl})$ & $P$-value \\
\hline $\begin{array}{l}\text { IGCCCG risk groups (good/intermediate } \\
\text { vs poor risk) }\end{array}$ & $0.142(0.032-0.623)$ & 0.010 \\
\hline Haemoglobin $\left(\mathrm{gl}^{-1}\right)$ & $0.983(0.958-1.007)$ & 0.17 \\
\hline $\begin{array}{l}\text { IGCCCG risk groups (good/intermediate } \\
\text { vs poor risk) }\end{array}$ & $7.26(2.03-26.0)$ & 0.002 \\
\hline Leukocytes $\left(10^{3}\right.$ per $\left.\mu l\right)$ & $1.27(1.06-1.54)$ & 0.011 \\
\hline $\begin{array}{l}\text { IGCCCG risk groups (good/intermediate } \\
\text { vs poor risk) }\end{array}$ & $0.180(0.047-0.686)$ & 0.012 \\
\hline Neutrophils $\left(10^{3}\right.$ per $\mu$ l) & $1.47(1.09-1.98)$ & 0.011 \\
\hline $\begin{array}{l}\text { IGCCCG risk groups (good/intermediate } \\
\text { vs poor risk) }\end{array}$ & $0.117(0.017-0.810)$ & 0.030 \\
\hline $\operatorname{CRP}\left(\mathrm{mgl}^{-1}\right)$ & $1.01(1.00-1.02)$ & 0.062 \\
\hline $\begin{array}{l}\text { IGCCCG risk groups (good/intermediate } \\
\text { vs poor risk) }\end{array}$ & $0.131-0.008-2.12)$ & 0.15 \\
\hline Albumin $\left(\left.g\right|^{-1}\right)$ & $0.981(0.768-1.25)$ & 0.88 \\
\hline $\begin{array}{l}\text { IGCCCG risk groups (good/intermediate } \\
\text { vs poor risk) }\end{array}$ & $0.130(0.036-0.464)$ & 0.002 \\
\hline$N L R^{a}$ & $84.5(2.2-3193)$ & 0.017 \\
\hline $\begin{array}{l}\text { IGCCCG risk groups (good/intermediate } \\
\text { vs poor risk) }\end{array}$ & $0.161(0.042-0.615)$ & 0.008 \\
\hline SII & $12.1(1.17-126)$ & 0.037 \\
\hline $\begin{array}{l}\text { Abbreviations: } \mathrm{Cl}=\text { confidence interval; } \mathrm{CRP}= \\
\text { IGCCCG = International Germ Cell Cancer } \mathrm{Co} \\
\text { lymphocytes ratio; } \mathrm{SII}=\text { systemic immune-inflamr } \\
{ }^{\mathrm{a}} \text { After log } 10 \text { transformation: the HR thus corresp } \\
\text { bold } P \text {-values indicate statistical significance. }\end{array}$ & $\begin{array}{l}\text {-reactive protein; HR= } \\
\text { aborative Group; NLR=n } \\
\text { tion index. } \\
\text { ds to a } 10 \text {-fold increase o }\end{array}$ & $\begin{array}{l}\text { zard ratio; } \\
\text { trophils-to- } \\
\text { ne variable }\end{array}$ \\
\hline
\end{tabular}

potent chemotherapy regimens, a subset of patients still fails firstline chemotherapy and some of those patients eventually die from their disease. Identification of these high-risk patients could trigger 

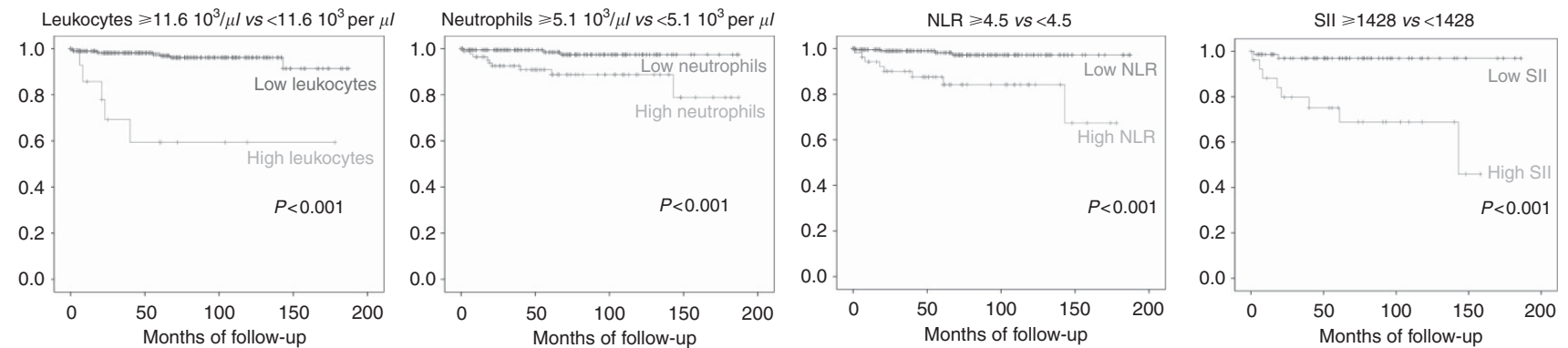

Figure 1. Kaplan-Meier curves split by leukocyte count, neutrophil count, neutrophil-to-lymphocytes ratio (NLR) and systemic immuneinflammation index (SII).

a closer follow-up schedule or an intensified treatment algorithm for these patients. In the present investigation, we were able to show, to the best of our knowledge for the first time, that different markers of systemic inflammation (namely leukocytes, neutrophils, NLR and SII) have the potential to improve prediction of oncologic outcome in patients with metastatic GCT in addition to the wellestablished IGCCCG classification system. Improved prediction of oncologic outcome might impact the decision of what systemic treatment a patient will receive and thus, might lead to more personalised and eventually more effective treatment decision for selected patients with metastatic GCT.

The IGCCCG risk classification has been shown to be an independent predictor of oncologic outcome for patients with metastatic GCT (International-Germ-Cell-Cancer-CollaborativeGroup, 1997). The classification system was published in 1997 and is based on multi-institutional data of patients treated between 1975 and 1990. Since then, improvements in diagnostics (mainly imaging) but also novel treatment protocols and more standardised follow-up regimens have been implemented into testis cancer care. It is likely that these changes in disease management have an impact on the validity of the 'historical' IGCCCG classification. An update of the IGCCCG classification system using a more contemporary patient cohort is currently in preparation (Collette and Assele, 2017). This update is likely to more precisely predict the oncologic outcome of contemporary patients with metastatic GCT. In addition, it offers the opportunity to test new promising variables such as novel biomarkers or information from genetic testing and imaging studies, which might further improve risk prediction traditionally based only on conventional clinicopathological parameters.

Cancer-related inflammation had initially been thought to be a pure anti-tumoural response of the host system. However, it became obvious that several immune mechanisms promote tumour development and progression such that inflammation is now regarded as one of the hallmarks of cancer (Grivennikov et al, 2010; Hanahan and Weinberg, 2011). For example, the innate immune system, represented by, for example, circulating neutrophils is thought to have a tumour-promoting role. In contrast, immune cells of the adaptive system (e.g., lymphocytes) represent the anti-tumour system. Thus, the pro-tumour or anti-tumour activity of the different immune cells determines whether high levels of these cells predict a favourable or unfavourable prognosis. Many of the exact underlying inflammatory mechanisms are still incompletely understood, but it is known that they include the supply of factors by immune cells and tumour cells (e.g., growth factors, pro-inflammatory cytokines, angiogenic factors and enzymes modifying the tumour microenvironment) (Hanahan and Weinberg, 2011). For example, interleukin-6, which is increased in patients with different neoplasms, is known to upregulate the synthesis of acute phase proteins including CRP and to downregulate the albumin production in the liver (Ohsugi, 2007; Lippitz, 2013).
Given the role of inflammation in tumour biology, there is a biological rationale for the use of inflammatory markers to predict cancer outcome. It has been shown that the utility of inflammatory markers varies between different tumours (Templeton et al, $2014 \mathrm{~b}$ ). If chronic inflammatory processes are the reason for tumour development (e.g., in asbestosis-related mesothelioma), inflammatory markers are known to be of particular value for outcome prediction (Templeton et al, 2014b). In GCTs, inflammatory processes can also be detected (e.g., tumour infiltrating lymphocytes as a typical feature of seminoma, (Emerson and Ulbright, 2007)) indicating that inflammatory markers might be of value for GCT. Furthermore, it has been shown that more advanced and metastatic disease is often associated with higher inflammatory markers that might be due to either prolonged chronic inflammatory processes or simply a greater tumour burden (Templeton et al, 2014b). Higher neutrophils and leukocytes where also found in patients with brain, bone or visceral metastases in the present investigation.

Systemic inflammatory markers are very attractive prognosticators because they can easily be retrieved from routinely performed, inexpensive blood tests. Single markers from CBCs such as leukocytes, platelets and haemoglobin have been shown to have prognostic potential for many malignant tumours (Manegold, 1998; Ishizuka et al, 2013; Hamai et al, 2014; Templeton et al, 2014a; Grimm et al, 2016). Non-CBC markers (e.g., CRP and albumin) have also been found to be of prognostic utility in a variety of malignancies (Forrest et al, 2003; Al Murri et al, 2006; McMillan et al, 2007; Saito and Kihara, 2013; Dai et al, 2014; Huang et al, 2015; Shrotriya et al, 2015). In the present investigation, leukocytes and neutrophils remained significant predictors of oncologic outcome besides the IGCCCG risk groups.

Besides these single-parameter markers, several ratios of different parameters (e.g., NLR, PLR, SII) have been investigated. These markers take the different pro-tumour and anti-tumour activity of different immune cells into account, and thus, are thought to better reflect the actual inflammatory response associated with initiation and progression of a malignant tumour. Neutrophils-to-lymphocytes-ratio is the most extensively investigated ratio and has been shown to be a strong prognosticator in many malignancies (Templeton et al, 2014a). The more recently developed marker SII, a combination of NLR and PLR has also been shown to predict oncologic outcome in several tumours including GCT (Hu et al, 2014; Lolli et al, 2016; Chovanec et al, 2017). In the present investigation, both, NLR and SII remained independent predictors of OS besides the IGCCCG risk groups.

There is most likely some redundancy and overlap between the different inflammatory markers. Bhindi et al (2016) were able to show that for patients with bladder cancer undergoing radical cystectomy single CBC markers were outperformed by ratios of different markers in terms of prediction of oncologic outcome. In their investigation, which did not include the SII marker, NLR was the only independent predictor for all three investigated outcomes 
(i.e., recurrence-free survival, cancer-specific survival and OS). In the present investigation, we were not able to determine which inflammatory marker or which combination of markers most efficiently predicts oncologic outcome in combination with the IGCCCG risk classification, due to our limited number of events. It was not possible to test more than one systematic inflammatory marker in the same multivariate analysis together with IGCCCG risk groups. Thus, our analyses should rather be considered exploratory than confirmatory. In addition, multiple testing may lead to type I errors, which might overestimate the described associations between inflammatory markers and oncologic outcomes. However, multiple testing is justifiable in a hypothesisgenerating exploratory analysis. Hence, our results show that inflammatory markers have the potential to improve prediction of oncologic outcome, but ultimately, a larger data set is needed to exactly determine which markers will be useful in clinical practice.

In conclusion, several systemic inflammatory markers, which are available from routinely performed inexpensive blood tests, demonstrated incremental prognostic information in addition to the IGCCCG risk groups for patients with metastatic GCT undergoing first-line chemotherapy. The planned IGCCCG update might be an opportunity to elucidate which inflammatory markers would ultimately possess the greatest potential to predict oncologic outcomes besides the IGCCCG classification in this patient population.

\section{CONFLICT OF INTEREST}

The authors declare no conflict of interest.

\section{REFERENCES}

Al Murri AM, Bartlett JM, Canney PA, Doughty JC, Wilson C, McMillan DC (2006) Evaluation of an inflammation-based prognostic score (GPS) in patients with metastatic breast cancer. Br J Cancer 94(2): 227-230.

Azab B, Bhatt VR, Phookan J, Murukutla S, Kohn N, Terjanian T, Widmann WD (2012) Usefulness of the neutrophil-to-lymphocyte ratio in predicting short- and long-term mortality in breast cancer patients. Ann Surg Oncol 19(1): 217-224.

Bhindi B, Hermanns T, Wei Y, Yu J, Richard PO, Wettstein MS, Templeton A, Li K, Sridhar SS, Jewett MA, Fleshner NE, Zlotta AR, Kulkarni GS (2016) Identification of the best complete blood count-based predictors for bladder cancer outcomes in patients undergoing radical cystectomy. $\mathrm{Br} \mathrm{J}$ Cancer 114(2): 207-212.

Chovanec M, Cierna Z, Miskovska V, Machalekova K, Kalavska K, Rejlekova K, Svetlovska D, Macak D, Spanik S, Kajo K, Babal P, Mardiak J, Mego M (2017) Systemic immune-inflammation index is prognostic in testicular germ cell tumors with PD-L1 expressing tumor infiltrating lymphocytes. J Clin Oncol 35(15 suppl): e16042-e16042.

Chung P, Daugaard G, Tyldesley S, Atenafu EG, Panzarella T,

Kollmannsberger C, Warde P (2015) Evaluation of a prognostic model for risk of relapse in stage I seminoma surveillance. Cancer Med 4(1): 155-160.

Collette L, Assele S (2017) Update of the international prognostic classification for first line metastatic germ-cell cancers. An international initiative. Eur J Cancer 72: S196-S197.

Dai J, Tang K, Xiao W, Yu G, Zeng J, Li W, Zhang YQ, Xu H, Chen ZQ, Ye ZQ (2014) Prognostic significance of C-reactive protein in urological cancers: a systematic review and meta-analysis. Asian Pac J Cancer Prev 15(8): 3369-3375.

Daugaard G, Gundgaard MG, Mortensen MS, Agerbaek M, Holm NV, Rorth M, von der Maase H, Christensen IJ, Lauritsen J (2014) Surveillance for stage I nonseminoma testicular cancer: outcomes and long-term follow-up in a population-based cohort. J Clin Oncol 32(34): 3817-3823.

DeSantis CE, Lin CC, Mariotto AB, Siegel RL, Stein KD, Kramer JL, Alteri R, Robbins AS, Jemal A (2014) Cancer treatment and survivorship statistics, 2014. CA Cancer J Clin 64(4): 252-271.
Emerson RE, Ulbright TM (2007) Morphological approach to tumours of the testis and paratestis. J Clin Pathol 60(8): 866-880.

Forrest LM, McMillan DC, McArdle CS, Angerson WJ, Dunlop DJ (2003) Evaluation of cumulative prognostic scores based on the systemic inflammatory response in patients with inoperable non-small-cell lung cancer. Br J Cancer 89(6): 1028-1030.

Gandaglia G, Becker A, Trinh Q-D, Abdollah F, Schiffmann J, Roghmann F, Tian Z, Montorsi F, Briganti A, Karakiewicz PI, Sun M (2014) Long-term survival in patients with germ cell testicular cancer: a population-based competing-risks regression analysis. Eur J Surg Oncol 40(1): 103-112.

Grimm T, Buchner A, Schneevoigt B, Kretschmer A, Apfelbeck M, Grabbert M, Jokisch JF, Stief CG, Karl A (2016) Impact of preoperative haemoglobin and CRP levels on cancer-specific survival in patients undergoing radical cystectomy for transitional cell carcinoma of the bladder: results of a single-center study. World J Urol 34(5): 703-708.

Grivennikov SI, Greten FR, Karin M (2010) Immunity, inflammation, and cancer. Cell 140(6): 883-899.

Grivennikov SI, Karin M (2010) Inflammation and oncogenesis: a vicious connection. Curr Opin Genet Dev 20(1): 65-71.

Hamai Y, Hihara J, Taomoto J, Yamakita I, Ibuki Y, Okada M (2014) Haemoglobin level influences tumor response and survival after neoadjuvant chemoradiotherapy for esophageal squamous cell carcinoma. World J Surg 38(8): 2046-2051.

Hanahan D, Weinberg RA (2011) Hallmarks of cancer: the next generation. Cell 144(5): 646-674.

Hermanns T, Bhindi B, Wei Y, Yu J, Noon AP, Richard PO, Bhatt JR, Almatar A, Jewett MA, Fleshner NE, Zlotta AR, Templeton AJ, Kulkarni GS (2014) Pre-treatment neutrophil-to-lymphocyte ratio as predictor of adverse outcomes in patients undergoing radical cystectomy for urothelial carcinoma of the bladder. Br J Cancer 111(3): 444-451.

Hu B, Yang X-R, Xu Y, Sun Y-F, Sun C, Guo W, Zhang X, Wang W-M, Qiu S-J, Zhou J, Fan J (2014) Systemic immune-inflammation index predicts prognosis of patients after curative resection for hepatocellular carcinoma. Clin Cancer Res 20(23): 6212-6222.

Huang J, Baum Y, Alemozaffar M, Ogan K, Harris W, Kucuk O, Master VA (2015) C-reactive protein in urologic cancers. Mol Aspects Med 45: 28-36.

International-Germ-Cell-Cancer-Collaborative-Group (1997) International Germ Cell Consensus Classification: a prognostic factor-based staging system for metastatic germ cell cancers. International Germ Cell Cancer Collaborative Group. J Clin Oncol 15(2): 594-603.

Ishizuka M, Nagata H, Takagi K, Iwasaki Y, Kubota K (2013) Combination of platelet count and neutrophil to lymphocyte ratio is a useful predictor of postoperative survival in patients with colorectal cancer. Br J Cancer 109(2): 401-407.

Lippitz BE (2013) Cytokine patterns in patients with cancer: a systematic review. Lancet Oncol 14(6): e218-e228.

Lolli C, Basso U, Derosa L, Scarpi E, Sava T, Santoni M, Crabb SJ, Massari F, Aieta M, Conteduca V, Maruzzo M, La Russa F, Wheater M, Berardi R, Galli L, De Giorgi U (2016) Systemic immune-inflammation index predicts the clinical outcome in patients with metastatic renal cell cancer treated with sunitinib. Oncotarget 7(34): 54564-54571.

Manegold C (1998) The causes and prognostic significance of low haemoglobin levels in tumor patients. Strahlenther Onkol 174(Suppl 4): 17-19.

McMillan DC, Crozier JE, Canna K, Angerson WJ, McArdle CS (2007) Evaluation of an inflammation-based prognostic score (GPS) in patients undergoing resection for colon and rectal cancer. Int J Colorectal Dis 22(8): 881-886.

Ohsugi Y (2007) Recent advances in immunopathophysiology of interleukin6: an innovative therapeutic drug, tocilizumab (recombinant humanized anti-human interleukin- 6 receptor antibody), unveils the mysterious etiology of immune-mediated inflammatory diseases. Biol Pharm Bull 30(11): 2001-2006.

Saito K, Kihara K (2013) Role of C-reactive protein in urological cancers: a useful biomarker for predicting outcomes. Int J Urol 20(2): 161-171.

Sarraf KM, Belcher E, Raevsky E, Nicholson AG, Goldstraw P, Lim E (2009) Neutrophil/lymphocyte ratio and its association with survival after complete resection in non-small cell lung cancer. J Thorac Cardiovasc Surg 137(2): 425-428.

Shrotriya S, Walsh D, Bennani-Baiti N, Thomas S, Lorton C (2015) C-reactive protein is an important biomarker for prognosis tumor recurrence and treatment response in adult solid tumors: a systematic review. PLoS ONE 10(12): e0143080. 
Siegel RL, Miller KD, Jemal A (2017) Cancer statistics, 2017. CA Cancer J Clin 67(1): 7-30.

Templeton AJ, Ace O, McNamara MG, Al-Mubarak M, Vera-Badillo FE, Hermanns T, Seruga B, Ocana A, Tannock IF, Amir E (2014a) Prognostic role of platelet to lymphocyte ratio in solid tumors: a systematic review and meta-analysis. Cancer Epidemiol Biomarkers Prev 23(7): 1204-1212.

Templeton AJ, McNamara MG, Šeruga B, Vera-Badillo FE, Aneja P, Ocaña A, Leibowitz-Amit R, Sonpavde G, Knox JJ, Tran B, Tannock IF, Amir E (2014b) Prognostic role of neutrophil-to-lymphocyte ratio in solid tumors: a systematic review and meta-analysis. J Natl Cancer Inst 106(6): dju124.
Yamanaka T, Matsumoto S, Teramukai S, Ishiwata R, Nagai Y, Fukushima M (2007) The baseline ratio of neutrophils to lymphocytes is associated with patient prognosis in advanced gastric cancer. Oncology 73(3-4): 215-220. Youden WJ (1950) Index for rating diagnostic tests. Cancer 3(1): 32-35.

This work is published under the standard license to publish agreement. After 12 months the work will become freely available and the license terms will switch to a Creative Commons AttributionNonCommercial-Share Alike 4.0 Unported License. 